\title{
Contos tradicionais e as crianças: diálogos entre Portugal e Brasil
}

Claudia Leite Brandão

Ângela Balça

\section{Resumo}

O conto tradicional é marcado por características da narratividade e, por nascer da oralidade, é considerado um gênero importante que proporciona a leitores e ouvintes a inserção no mundo da literatura. Ademais, integra a cultura e o imaginário das pessoas, acompanhando-as ao longo do tempo. Pretende-se atribuir visibilidade ao gênero, com o objetivo de refletir acerca desse patrimônio cultural, por meio de análise do conto Caldo de pedra, na versão portuguesa, recolhida por Teófilo Braga, no século 19, e ainda na releitura em português de Portugal, escrita por Alice Vieira (2018) e ilustrada por Vanda Romão. Lançar-se-ão olhares, também, sobre a versão em português do Brasil, escrita por Ana Maria Machado (2004) e ilustrada por Odilon Moraes. Desse modo, importa reiterar que, para a seleção do conto, considera-se como mote Teófilo Braga, em sua obra Contos tradicionais do povo português. O procedimento metodológico baseia-se na revisão de literatura, com obras que versam sobre o tema referido. Norteia-se a construção deste artigo com base na concepção de que esse gênero atua, significativamente, na formação e ampliação do repertório da criança, seja leitora ou ouvinte.

Palavras-chave: conto tradicional; literatura infantil; leitor; leitura. 


\section{Abstract \\ Children and traditional short stories: dialogues between Portugal and Brazil}

Characteristics of narrativity leave a mark on the traditional short story which, arising from orality, becomes relevant as a genre that offers readers and listeners a way into the literary world. Thus, it integrates people's culture and imagination, accompanying them over time. This paper raises the visibility of traditional short stories, in order to reflect on this cultural heritage, through an analysis of the Portuguese version of the short story Caldo de pedra, gathered by Téofilo Braga, in the 19th century; and of the Portuguese from Portugal re-telling of this story written by Alice Vieira (2018) and illustrated by Vanda Romão. The Brazilian Portuguese version, written by Ana Maria Machado (2004) and illustrated by Odilon Moraes, will also be analyzed. Thus, it is important to reconfirm that, for the selection of this short story, this study takes as grounding Téofilo Braga's work - Contos Tradicionais do Povo Português. The literature review substantiates this methodological procedure, with writings that discuss the theme. This work is developed under the concept that traditional short stories significantly influence children's education and knowledge improvement, whether as reader or listener.

Keywords: traditional short story; children's literature; reader; reading.

\section{Resumen \\ Cuentos tradicionales y los niños: diálogos entre Portugal y Brasil}

El cuento tradicional está marcado por características de la narratividad y, por nacer de la oralidad, es considerado un género importante que proporciona a lectores y oyentes la inserción en el mundo de la literatura. Además, integra la cultura y el imaginario de las personas, acompañándolas a lo largo del tiempo. Por lo tanto, este artículo pretende asignar visibilidad a los cuentos tradicionales, con el fin de reflexionar sobre este patrimonio cultural, por medio del análisis del cuento Caldo de Pedra, en la versión portuguesa, recogida por Teófilo Braga, en el siglo 19, y también en la relectura en portugués de Portugal, escrita por Alice Vieira (2018) e ilustrada por Vanda Romão. Se enfocará, también, acerca de la versión en portugués de Brasil, escrita por Ana María Machado (2004) e ilustrada por Odilon Moraes. De ese modo, es importante reiterar que, para la selección del cuento, este estudio tiene como tema Teófilo Braga, en su obra Cuentos tradicionales del pueblo portugués. El procedimiento metodológico se basa en la revisión de literatura, con obras que versan sobre el tema referido. Se orienta la construcción de este trabajo por medio de la concepción de que los cuentos tradicionales actúan, significativamente, en la formación y ampliación del repertorio de los niños, sea lector u oyente.

Palabras clave: cuento tradicional; literatura infantil; lector; lectura. 


\section{Introdução}

Os contos tradicionais são imensamente simpáticos às crianças, e já Platão os considerava como um excelente meio de educação. (Braga, 1999, p. 9).

O conto tradicional é marcado por características da narratividade e, por nascer da oralidade, é considerado um gênero importante que proporciona a leitores e ouvintes a inserção no mundo da literatura. Ademais, integra a cultura e o imaginário das pessoas, acompanhando-as ao longo do tempo. Segundo Azevedo (2007, p. 2), contos tradicionais

[...] são típicas expressões de culturas orais (sem escrita), ou seja, culturas que não contam com recursos para fixar informações. De narrador em narrador, guardados, através dos séculos, na plasticidade da memória e da voz, viajaram para todos os lados sendo disseminados pela transmissão boca a boca.

Diante disso, diferentes narrativas percorrem e influenciam uma diversidade de culturas. Cascudo (2014) ressalta que quando os portugueses emigraram para o Brasil trouxeram o seu "mundo em sua memória" e o mesmo aconteceu com os indígenas e os africanos. Complementarmente, Sales (2014) expõe que a literatura tradicional brasileira é composta por três etnias - a branca, a negra e a indígena para formar a memória que se estende desde as sociedades pré-colombianas até o povo atual. É pertinente explicitar que o conceito de literatura tradicional abordado neste estudo é aquele apresentado no E-Dicionário de Termos Literários:

[...] textos transmitidos de geração em geração, resultado de uma "criação colectiva", no sentido em que se desconhece o seu autor e em que sofreram ao longo dos tempos alterações que podem atingir diferentes níveis dos textos - nível estrutural, semântico, estilístico, vocabular - podendo dar origem a versões diferentes do texto tradicional. (Pires, 2009).

Com isso, para além do conto, outras manifestações, como folclore, mitos e lendas, adaptaram-se umas às outras e, utilizando elementos locais, aclimataram-se nesse solo. Balça (2015, p. 28) aponta que "os contos tradicionais estão presentes em diversos pontos do globo, distantes geograficamente, mas que apresentam uma similitude enorme".

Candido (2010) afirma que a literatura brasileira foi gerada no seio da literatura portuguesa. Outra influência é atribuída ao início das edições de livros para crianças, pois "a maior parte da literatura infantil e praticamente todos os livros para as crianças menores vinham de Portugal; e mesmo a pequena parte produzida no Brasil ainda seguia, na linguagem, os usos da pátria-mãe" (Hallewell, 2005, p. 274). Assim, uma diversidade de contos tradicionais coletados por Teófilo Braga, no século 19, em Portugal, encontrou acolhida e repercutiu na cultura brasileira. Cabe destacar dois autores que deixaram um enorme legado da literatura tradicional entre Portugal e Brasil: Braga (1999), com sua obra Contos tradicionais do povo português, e Cascudo (2014), com a coletânea Contos tradicionais do Brasil.

Em função disso, este artigo pretende atribuir visibilidade aos contos tradicionais, com o objetivo de refletir acerca desse patrimônio cultural, por meio 
de análise do conto Caldo de pedra, na versão portuguesa, recolhida por Teófilo Braga, no século 19, e ainda na releitura em português de Portugal, escrita por Alice Vieira (2018) e ilustrada por Vanda Romão. Lançar-se-ão olhares, também, sobre a versão em português do Brasil, escrita por Ana Maria Machado (2004) e ilustrada por Odilon Moraes.

Alguns critérios foram utilizados para as escolhas das releituras. A obra Histórias tradicionais portuguesas, de Alice Vieira (2018), foi selecionada por fazer parte do catálogo dos livros recomendados para crianças de 6 a 8 anos de idade, em Portugal, no Plano Nacional de Leitura (PNL), ${ }^{1}$ de 2018. Já a obra Histórias à brasileira: Pedro Malasartes e outras, recontadas por Ana Maria Machado (2004), também foi escolhida por ter feito parte de um programa de incentivo à leitura no Brasil, pois, em 2005, foi distribuída pelo Programa Nacional Biblioteca da Escola (PNBE)² para os alunos dos anos iniciais do ensino fundamental das escolas públicas.

A versão em português de Portugal, escrita por Alice Vieira (2018) e ilustrada por Vanda Romão, com o título Histórias tradicionais portuguesas, apresenta duas narrativas populares: A sopa da pedra e O ladrão debaixo da cama. A escritora é considerada uma das mais importantes autoras portuguesas de literatura infantil e juvenil, tanto que já recebeu vários prêmios literários e suas obras são traduzidas para várias línguas. Convergente a isso, destacamos que, em 2016, o título Meia hora para mudar a minha vida foi considerado o melhor livro de literatura em língua portuguesa e recebeu o prêmio Henriqueta Lisboa, da Fundação Nacional do Livro Infantil e Juvenil (FNLIJ), no Brasil.

A escritora Ana Maria Machado e o ilustrador Odilon Moraes lançaram, em três volumes, as Histórias à brasileira, trazendo contos tradicionais que fazem parte da cultura brasileira. O texto da contracapa da obra esclarece que "o projeto nasceu do desejo da autora de contar, com suas palavras, as histórias que havia escutado de seus pais e da avó", e na apresentação do livro, a escritora explica que é oriunda "de uma família em que se contava muita história. Com ou sem livro. E os repertórios variavam muito, de acordo com o contador" (Machado, 2004). Ana Maria Machado tem centenas de livros publicados e diversos prêmios literários, como Jabuti, Machado de Assis e Hans Christian Andersen.

Curiosamente, além das várias produções literárias e premiações, Vieira e Machado possuem outras familiaridades entre si, pois as duas inicialmente eram jornalistas e, em certo período de suas vidas, fizeram a opção pela escrita de livros. De fato, temos, assim, obras com autorias renomadas no contexto das produções literárias, em Portugal e no Brasil, seja para o público infantil, juvenil, ou até mesmo adulto.

\footnotetext{
${ }^{1}$ O PNL tem como finalidade elevar os níveis de literacia dos portugueses e, por isso, é uma iniciativa governamental sob a responsabilidade do Ministério da Educação, do Ministério da Cultura e do Gabinete do Ministro dos Assuntos Parlamentares.

${ }^{2}$ O PNBE foi uma ação governamental de 1997 a 2017 que tinha como finalidade a distribuição de obras literárias para as escolas públicas brasileiras.
} 


\section{Conto tradicional: encontro entre memória e imaginação}

O valor do conto não é apenas emocional e delicioso, é uma viagem de retorno ao país da infância. (Cascudo, 2014, p. 5).

A escolha do subtítulo parte do princípio defendido por Cascudo (2014, p. 6) de que o conto, como gênero narrativo, é o ponto de encontro entre a memória e a imaginação, visto que a memória preserva os traços gerais e a imaginação vai modificando e ampliando "por assimilação, enxertos ou abandonos de pormenores, certos aspectos da narrativa". O autor expõe que o conto tradicional "revela informação histórica, etnográfica, sociológica, jurídica, social. É um documento vivo, denunciando costumes, ideias, mentalidades, decisões e julgamentos" (Cascudo, 2014, p. 6).

De modo geral, os contos tradicionais integram a cultura e o imaginário das pessoas, acompanhando-as de forma atemporal. Um mesmo conto pode ser narrado de diferentes formas, depende de quem conta e da relação entre narrador, narrativa e público. Segundo Coelho (2000), mesmo gerados em épocas diferentes, embora venham sendo reescritos ou readaptados através dos tempos, os contos preservam, em sua visão de mundo, os valores básicos do momento em que surgiram, ou seja, transmitem determinados valores ou normas a serem respeitados de forma coletiva ou inseridos no comportamento individual.

Por meio dos contos, crianças, jovens e adultos podem se inserir no contexto cultural de um povo para conhecer outras culturas e, principalmente, para reconhecer a sua. No entendimento teórico de Candido (2010, p. 83), a literatura, principalmente por sua função humanizadora, é uma forma de expressão que manifesta as emoções e a visão de mundo de indivíduos e grupos. Conforme o autor:

\footnotetext{
A literatura propriamente dita é uma das modalidades que funcionam como resposta a essa necessidade universal, cujas formas mais humildes e espontâneas de satisfação talvez sejam coisas como a anedota, a adivinha, o trocadilho, o rifão. Em nível complexo surgem as narrativas populares, os cantos folclóricos, as lendas, os mitos. (Candido, 2010, p. 83).
}

Em outras palavras, Balça (2015, p. 29) ressalta que é mediante as reescritas desses textos que nos apropriamos de parte do imaginário subjacente do nosso mundo. Esse imaginário nos permite sentir pertencentes a um determinado universo, "daquele e não de outro, partilhando ideias, valores, sentimentos, formas de ser, formas de estar, formas de ler o mundo".

Diante do exposto, para este estudo, destacamos o conto Caldo de pedra, uma narrativa recuperada da tradição oral por Teófilo Braga, na cidade do Porto, em Portugal, no século 19.

A narrativa centra-se em um frade que andava ao peditório e, ao chegar à casa de um lavrador, por estar com muita fome, pediu comida. O senhor da casa não quis lhe dar nada. Com isso, o frade disse: 
- Vou ver se faço um caldinho de pedra. E pegou numa pedra do chão, sacudiulhe a terra e pôs-se a olhar para ela para ver se era boa para fazer um caldo. As pessoas da casa ficaram rindo e o frade perguntou: - Então nunca comeram caldo de pedra? Só lhes digo que é uma coisa muito boa. (Braga, 1999, p. 209).

O que o frade queria era deixá-los curiosos para o seu preparo. Ao começar, a única coisa que tinha era a pedra, então, logo pediu uma panela emprestada. Depois, a cada passo, mais ingredientes (sal, couve, chouriço, pão) eram solicitados, até que resultou em um excelente caldinho. Quando estava finalizado o caldo: "Comeu e lambeu o beiço; depois de despejada a panela, ficou a pedra no fundo; a gente da casa, que estava com os olhos nele, perguntou-lhe: - Ó senhor frade, então a pedra?" (Braga, 1999, p. 209). O frade simplesmente respondeu que a pedra ele lavava e carregava para outra vez poder comer onde não lhe dessem comida.

O conto apresenta dois fatos: um frade com muita fome e a sua esperteza para lidar com a situação. Para Castañeda (2005, p. 36), nesse tipo de conto, verificase que a intenção, "em razão da comicidade, pode ser mais profunda que o simples destaque daquilo que se repreende ou reprova, e que essa forma nem sempre significa zombaria, mas também um meio de se passar da tensão à distensão, ao relaxamento".

Essa narrativa se enquadra, na classificação de Braga (1999) e Cascudo (2014, p. 12), como facécia, ou seja, "contos para fazer rir, patranhas, muitas vezes revelam extrema crueldade e profundos preconceitos". Em relação à narrativa, o conto se caracteriza como forma simples porque resulta de uma "criação espontânea" e, a partir do surgimento anônimo, passa a circular entre os povos (Coelho, 2000).

A circulação dos contos populares entre os povos, de boca em boca, muitas vezes, caracteriza-se como marca cultural de determinada localidade. Em Portugal, na cidade de Almeirim, a sopa da pedra é considerada a sopa típica portuguesa, a designação está associada ao conto tradicional. Por conta da popularidade da tradição, nessa cidade, todos os anos acontece um festival de vários dias, no final de agosto ou início de setembro, e, no site da Câmara Municipal de Almeirim, encontra-se a receita oficial (Quadro 1) e a descrição do conto.

\section{Quadro 1 - Receita oficial da sopa da pedra de Almeirim}

\begin{tabular}{|l|l|}
\multicolumn{1}{|c|}{ INGREDIENTES } & \multicolumn{1}{|c}{ MODO DE FAZER } \\
\hline$-2,5$ l de água & Ponha o feijão a demolhar de um dia para o outro. \\
-1 kg de feijão vermelho & De véspera escalde e raspe a orelha de porco de modo a \\
-1 orelha de porco & ficar bem limpa. \\
-1 chouriço de carne & No próprio dia, leve o feijão a cozer em água, juntamente \\
-1 chouriço de sangue (morcela) & com a orelha, os enchidos, o toucinho, as cebolas, os \\
- 200 g de toucinho & mais água, se for necessário. Quando as carnes e os \\
-2 cebolas & enchidos estiverem cozidos, tire-os do lume e corte-os \\
-2 dentes de alho & em bocados. \\
-700 g de batatas & Junte, então, à panela as batatas, cortadas em cubinhos \\
-1 molho de coentros & e os coentros bem picados. \\
- Sal, louro e pimenta a gosto & Deixe ferver lentamente até a batata estar cozida. Tire a \\
& panela do lume e introduza as carnes previamente \\
& cortadas. \\
& No fundo da terrina onde vai servir a sopa coloque uma \\
& pedra bem lavada. \\
\hline
\end{tabular}

Fonte: Almeirim (2018). 
Existe um contraponto no preparo da sopa com o conto, pois, neste, a pedra inicia a preparação da sopa, enquanto, na receita, ela é colocada no fim.

No Brasil, para este estudo, não encontramos a origem da escrita da recolha do conto Caldo de pedra. Realizamos o mapeamento em alguns materiais, como Contos da carochinha, de 1894, escrito por Figueiredo Pimentel, e Contos populares brasileiros, de 1916, republicado em 2014, de autoria de Lindolfo Gomes; porém, não obtivemos sucesso na localização do registro.

Vários estudos, materiais didáticos e literários apontam que o conto foi recolhido por Luís da Câmara Cascudo (2014) e estaria registrado na coletânea Contos tradicionais do Brasil; todavia, procuramos em diferentes obras do referido autor e não encontramos o registro do conto. A pesquisa, inclusive, foi realizada com auxílio de uma profissional do Instituto Câmara Cascudo - Ludovicus, na cidade de Natal, Rio Grande do Norte. ${ }^{3}$ Entretanto, a falta dessa informação não retira o mérito da escolha do conto, pois como afirma Azevedo (2007, p. 2), "os contos populares são tão ricos, multifacetados e complexos" que a pretensão em identificar a sua verdadeira origem costuma ser perda de tempo.

As releituras dos contos tradicionais se espalharam por diferentes localidades do continente, em diversos campos da arte (pintura, música, cinema) e no universo midiático (jogos, desenhos, blogs). No entanto, neste trabalho, o nosso interesse recai apenas sobre as versões apresentadas no livro impresso, cujos sujeitos leitores são/serão as crianças. Ao considerar a situação, Ramos (2016, p. 36) discorre que, a partir dos anos 1970 e 1980, publicam-se, com mais assiduidade, para o público infantil, obras com "a reescrita da tradição oral, tanto em termos de procura de fidelidade e de divulgação dos textos [quanto] por meio das versões e das adaptações em que se distinguem [...]".

Para Cecília Meireles (2016, p. 64):

Insistimos na permanência do tradicional na literatura infantil, tanto oral quanto como escrito, porque por ele vemos um caminho de comunicação humana desde a infância que, vencendo o tempo e as distâncias, nos permite uma identidade de formação. Por essa comunhão de histórias, que é uma comunhão de ensinamentos, de estilos de pensar, moralizar e viver, o mundo parece tornar-se fácil, permeável a uma sociabilidade que tanto se discute.

Por conseguinte, apresentamos as versões do conto tradicional, com base na perspectiva da adaptação para crianças. Nas palavras de Ramos e Panozzo (2015, p. 88),

a adaptação é uma peculiaridade que está na origem do gênero literatura infantil, já que as primeiras histórias destinadas aos infantes eram recontadas visando à criança, a partir de contos populares que circulavam entre os adultos ou mesmo simplificadas a partir de obras clássicas. As obras adaptadas, em geral, chegam ao leitor por meio da forma narrativa [...].

Nessa direção, a narrativa A sopa da pedra é uma releitura contemporânea e traz um diferencial, tanto na estrutura do texto quanto na composição das imagens.

\footnotetext{
${ }^{3}$ Instituto Câmara Cascudo - Ludovicus. Disponível em: < http://www.cascudo.org.br/acervos/ bibliografico>.
} 
A escritora Alice Vieira não utiliza o recurso narrativo "conta-se que", "era uma vez", para começar a história. O texto se inicia, conforme se pode perceber, com um ato poético, ao ressaltar as pessoas que "nunca se sentem bem quando estão muito tempo no mesmo lugar. Se há muitas árvores - têm saudades do mar. Se há muito mar - têm saudades das montanhas. Se há muitas montanhas - têm saudades das planícies. E por aí fora. Frei Gil era uma dessas pessoas" (Vieira, 2018, p. 3).

Outra contraposição entre as versões é que, no Caldo de pedra, o frade faz um papel de pedinte e, n'A sopa de pedra, frei Gil não quer ser visto como pedinte, quer usar o "encantamento" da pedra para conseguir a comida. Sobre a questão da fome, Coelho (2000) estabelece que o motivo da efabulação, na maioria das vezes, é desenvolvido com base em três necessidades humanas: fome, sexo e poder, motivos que surgem nas narrativas primordiais; no entanto, persistem através dos séculos até os dias atuais, e, o que se altera é a representação simbólica e a reação das personagens.

A primeira imagem da obra A sopa de pedra é a de frei Gil saindo do mar. Por meio dela, percebemos que o personagem tem um semblante calmo e amável. Associando o início poético da narrativa às imagens e à nomeação do protagonista, notamos que essa nova versão desconstrói o frade astuto e ardiloso apresentado no Caldo de pedra, de Braga (1999).

A narrativa de A sopa de pedra traz o conflito da fome de maneira delicada. A senhora que atende o frei Gil demonstra prontidão para lhe dar esmola. Nenhum dos personagens é caracterizado com falas ou gestos de desdenho ou maldade, até o som das palavras soa com ar de delicadeza ("um favorzinho...").

- Precisa de alguma coisa, irmão? Esta casa é pobre, mas nunca deixámos de dar uma esmola a quem nos bate ao ferrolho!!

- Obrigado, essas são palavras de uma alma boa! - disse frei Gil. - Mas não bati à porta para pedir esmola. Queria apenas pedir um favor. Um favorzinho.... Coisa de nada. (Vieira, 2018, p. 3).

A velha não apresenta nome na história, mas, em todo o enredo, demonstrase amigável, alegre, caridosa e inocente. Inclusive, diverte-se, pois não vê a hora de contar para sua comadre a proeza do frei em fazer a sopa da pedra: "Água quente e uma pedra... - murmurava a velha. - Quem havia de dizer que era o suficiente para fazer sopa! Quando a comadre Cremilde souber, nem vai acreditar!" (Vieira, 2018, p. 11).

Ramos (2016, p. 37) reitera que a reescrita da tradição oral tem buscado a recriação de universos próximos dos infantis, com um "[...] domínio mais realista, os percursos, em diferentes modos, são feitos pela via de introspecção, com valorização do olhar, dos afetos, dos universos familiares e das vivências quotidianas".

A versão de Vieira (2018), em relação ao texto de Braga (1999), apresenta a mesma estrutura, o mesmo esquema narrativo, entretanto, destaca-se por complementos que se manifestam no texto e nas ilustrações. Por exemplo, o frei Gil demonstra mais atributos religiosos que o frade da versão portuguesa. Pensamos 
que a esperteza evidenciada na narrativa de Braga (1999), aparentemente, não condiz com uma personalidade religiosa.

Frei Gil tem a mesma ação, que é utilizar o pretexto da pedra para angariar os ingredientes da sopa, porém, a desenvoltura do protagonista é outra, a caracterização do enredo é mais detalhada e as imagens passam a sua vivência religiosa, ou seja, as ilustrações possibilitam conhecer o personagem. Sobre a personalização dos frades nos dois enredos, é pertinente destacar que, "na maioria das vezes, os contos populares, ou de encantamento, não obedecem a uma moral de princípios. Em tese, a moral corresponde a um conjunto de normas de comportamento destinadas a regular as relações entre os indivíduos" (Azevedo, 2007, p. 3).

Para dar sequência, em função da intenção do texto, agora destacamos a versão em português do Brasil, Pedro Malasartes e a sopa de pedra, escrita por Ana Maria Machado (2004) e ilustrada por Odilon Moraes.

Cascudo (2014, p. 25) assegura que "as estórias mais populares no Brasil não são as mais regionais ou julgadamente nascidas no país, mas aquelas de caráter universal, antigas, seculares, espalhadas por quase toda a superfície da terra". É por esse caráter universal que queremos iniciar falando do personagem Pedro Malasartes, o protagonista da releitura na versão em português do Brasil. Cascudo (2014) revela que em 1882, na obra Tradições populares de Portugal, José Leite de Vasconcellos registrou uma história tradicional sobre aventuras de Pedro Malasarte, dizendo que era barbeiro e, com isso, cortava a língua do ladrão que estava guardando o jantar, pois tinha a intenção de comer a refeição.

Malasartes é um personagem descarado e cheio de malandragem que, por meio da esperteza, enganava e trapaceava as pessoas. Ele está presente em diferentes culturas, "Malasarte português, Urdemales espanhol, é um centro de interesse reunindo estórias de muitas origens, castelhanas, francesas, italianas" (Cascudo, 2014, p. 194). No entanto, mesmo com as adaptações culturais, a esperteza sempre está presente para o sucesso das suas artimanhas e o êxito em suas trapaças. Na obra Contos da carochinha, Pimentel (1894, p. 29), com o conto Pedro Malasartes, faz uma caracterização para o personagem: "Pedro Malasarte ou Pedro das Malas Artes era assim chamado devido às inúmeras travessuras e mais artes que vivia a fazer para desespero da sua família. Desde muito pequeno o Pedrinho foi levado da breca, incorrigível". Já Cascudo (2014, p. 180), no conto Seis aventuras de Pedro Malazarte, atribuiu outros adjetivos, como "este tão astucioso e vadio", "ardiloso por natureza".

Cascudo (2014, p. 295) ainda comenta que o nome "Pedro é de 'São Pedro', dado como personagem astuto, um Sancho religioso, como o comparou Teófilo Braga". Malasartes traz um perfil caipira, rural, morador da roça. Ao primeiro olhar, o personagem quer demonstrar ingenuidade, no entanto, o que existe em seu caráter é uma verdadeira esperteza e astúcia, o famoso espertinho com cara de bobo. Para Coelho (2000, p. 179), "a esperteza/astúcia inteligentes vencem a prepotência e a força bruta; inclusive através de atos que julgados rigorosamente são desonestos, mas desculpados pela moral prática". 
O conto Pedro Malasartes e a sopa de pedra traz em seu início a marca das histórias tradicionais, ou seja, a voz do contador de histórias que Coelho (2000) assinala como o elo entre a situação narrada e o leitor: "Um dia, Pedro Malasartes vinha pela estrada com fome e chegou a uma casa onde morava uma velha pão dura" (Machado, 2004, p. 20). Encontramos essa mesma peculiaridade no texto de Braga (1999), pois se inicia com "um frade". Assim, percebemos que os contos se assemelham pelo recurso narrativo utilizado para sua transmissão e pela indeterminação deixada para o tempo (um dia) e para o personagem (um frade).

Sobre a maneira de adentrar na narrativa, Ana Maria Machado (2004) é mais direta, já que na primeira frase revela o motivo da história: a fome e a velha avarenta. Em sequência, utiliza o diálogo para caracterizar o personagem Pedro Malasartes:

- Sou um pobre viajante faminto e cansado. Venho andando de muito longe, há três anos, três meses, três semanas, três dias, três noites, três horas...

- Pare com isso e diga logo o que quer - interrompeu a mulher.

- É que estou com fome. Será que a senhora podia me ajudar?

- Não tem nada de comer nesta casa - foi logo dizendo a velha. (Machado, 2004, p. 20).

Aqui, como se vê, configura-se um personagem em uma situação sofrida, que expõe suas condições de "faminto" e "cansado" e, em seguida, reafirma que está "com fome" para investir e tentar garantir o seu pedido de ajuda. Como se constata, ele não consegue sensibilizar a velha e fica nítido o perfil dela de avarenta, sem valor humanitário. Após esse primeiro diálogo, o narrador descreve o cenário apontando os bens do local, para deixar mais clara a caracterização da velha.

Ele olhou em volta, viu um curral cheio de vacas, um galinheiro cheio de galinhas, umas gaiolas cheias de coelhos, um chiqueiro cheio de porcos. E mais uma horta muito bem cuidada, um pomar com árvores carregadinhas de frutas, um milharal viçoso, uma roça de mandioca. (Machado, 2004, p. 20 - grifo nosso).

Notamos que o uso de adjetivos de intensidade no trecho dá ênfase à quantidade de bens que a personagem (velha) possui e que, mesmo tendo muito, diz não haver na casa nada de comer. Com isso, Malasartes, que já explicamos que de bobo não tem nada, dá um jeito para mudar a situação e iniciar sua enganação.

- Não, a senhora entendeu mal. Eu não preciso de comida, não. Só queria era uma panela emprestada e um pouco d'água. Se a senhora me deixar usar seu fogão, eu já estou satisfeito. Porque aqui no chão tem muita pedra, e isso me basta. Eu faço uma sopa de pedra maravilhosa e nunca preciso de mais nada, já fico de barriga cheia. (Machado, 2004, p. 20-21).

A atitude do protagonista visa a uma aproximação da velha e, ao mesmo tempo, ao início de seu "truque" para conseguir o que deseja. No entanto, ele quer causar interesse na senhora, sem que ela perceba que será enganada. Como já vimos, nas três obras analisadas, após a apresentação da proposta de fazer o caldo ou a sopa de pedra para a personagem colaboradora (dona de casa, velhota e velha), era o momento de surpresa, curiosidade, espanto e dúvida: "sopa de pedra?" (Machado, 2004, p. 21).

Quanto ao interesse pela produção da sopa, avaliamos que, para a velha pão dura, alguns fatores se destacam para que ela tenha dúvida e, no decorrer da história, 
curiosidade e desejo em aprender a fazer a sopa: Produto para produção? Pedra! somada à fala de Malasartes de que a sopa fica maravilhosa e deixa a barriga cheia. Para quem é mesquinho, não teria alimento melhor, como ela diz: "- Se é uma sopa tão maravilhosa e tão econômica assim [...]" (Machado, 2004, p. 23).

O protagonista, durante a produção da sopa, instiga e motiva a velha para que ela se envolva no processo e caia nos seus "encantamentos".

- Está começando a ficar cheirosa, não acha?

- É mesmo - concordou a velha interessada.

- O problema é que vai ficar meio sem graça, assim branquela sem cor. O gosto está bom, mas fica sempre melhor quando a gente tem um pouco de colorido para enfeitar. Um pedaço de abóbora, umas folhas de couve, de repolho, uma cenourinha, uma batatinha... mas isso não é muito importante, a senhora não acha? É só aparência... (Machado, 2004, p. 23).

Por fim, Malasartes consegue se alimentar mediante sua artimanha em fazer a sopa de pedra, e, mesmo a senhora não querendo lhe dar o alimento, ele consegue se esbaldar e comer tudo do jeito que organizou, utilizando sua esperteza, sua lábia. Guimarães (2006, p. 23) afirma que tudo o que Malasartes consegue, mesmo "que ilicitamente, é entregue com as mãos do próprio dono, este dando tais mostras de burrice e desonestidade que, lesado, não tem coragem de reclamar".

É importante ressaltar que, nas releituras de Machado (2004) e Vieira (2018), quase todas as narrativas são construídas por meio do diálogo. Para Coelho (2000, p. 85), é um dos recursos que dá mais "objetividade às personagens e situações, pois é o que mais se aproxima da vida real". A autora ainda expõe que na "literatura infantil é das técnicas mais adequadas para atrair o pequeno leitor (ou ouvinte), exatamente porque a linguagem oral está mais perto de seu interesse do que a linguagem escrita" (Coelho, 2000, p. 86). Isso, também, pode ser associado ao pensamento de Azevedo (2007, p. 6), o qual destaca que:

\begin{abstract}
Mesmo em versões contemporâneas feitas por escrito, o conto popular continua marcado pela narrativa oral, pois tende a manter certas características do discurso falado e pressupõe sempre uma voz que narra e um ouvinte. Refirome a um escritor que de certo modo escreve como quem fala e a um leitor que lê como quem ouve.
\end{abstract}

Essas releituras receberam adaptações e foram transformadas com base nas influências de escritas e leituras das autoras, em especial, por ser uma obra destinada para o público infantil. As obras de Machado (2004) e Vieira (2018) mantêm o hipotexto de Braga (1999), no entanto, alargam-no apresentando detalhes, estendendo o texto. Para Calvino (2010, p. 97), "o mesmo esquema narrativo se encontra mais ou menos num país afastadíssimo e numa situação histórico-social absolutamente diferente".

Especificamente, o livro de Vieira (2018) trabalha com ilustrações que ampliam a narrativa, pois demonstram os detalhes do cenário e das personagens, bem como o semblante e as reações delas.

O hipotexto de Braga (1999), escrito de forma curta, apresenta tudo de modo indeterminado, nenhum personagem é nomeado, o tempo não é caracterizado. Já as outras duas obras possibilitam uma proximidade maior do leitor/ouvinte, o 
protagonista tem nome: frei Gil, em Portugal, e Pedro Malasartes, no Brasil. Vieira (2018) ainda acrescenta na história a dona Cremilde, amiga da velhota.

Diante de todos os detalhes, entendemos que a narrativa apresentada por Vieira (2018) denota o politicamente correto, todo o enredo e as ilustrações são delicados, o perfil do protagonista no decorrer da história é totalmente o contrário do frade e de Pedro Malasartes. As três escritas do conto seguem uma estrutura narrativa linear, demonstrando a sequência com início, meio e fim. O conto original é mais curto, enquanto nas releituras o texto foi ampliado e reescrito para o público infantil e juvenil.

Nessa acepção - as releituras analisadas parecem estabelecer a aproximação e a comunicação com as crianças leitoras/ouvintes -, o texto, por meio da imaginação e previsão dos acontecimentos da história, pode despertar o interesse para o acesso ao livro, para ler ou ouvir a narrativa. Balça (2015), no texto "Contos tradicionais: língua, cultura e imaginário", expõe que esses tipos de contos são importantes para as crianças, já que a forma lúdica da história mostra como os mais fracos podem vencer/inverter o conflito vivenciado com os mais fortes.

\section{Para não encerrar a prosa}

E como encontraram,

Tal qual encontrei;

Assim me contaram,

Assim vos contei!...

(Cascudo, 2010, p. 15).

Tínhamos como objetivo refletir sobre os contos tradicionais, por meio de análise do conto Caldo de pedra, na versão portuguesa, recolhida por Teófilo Braga, no século 19, e ainda na releitura em português de Portugal, escrita por Alice Vieira (2018) e ilustrada por Vanda Romão. Lançamos olhares, também, sobre a versão em português do Brasil, escrita por Ana Maria Machado (2004) e ilustrada por Odilon Moraes.

Ao realizar o estudo, procuramos demonstrar por meio do conto Caldo de pedra/Sopa de pedra que as narrativas tradicionais se estabelecem como patrimônio cultural em diferentes lugares, culturas e a cada nova geração. Como percebemos, o conto recolhido por Teófilo Braga não estava direcionado às crianças; no entanto, as releituras foram produzidas para um público infantil e juvenil. Nessa perspectiva, notamos que a narrativa tradicional deu origem a novas versões. Uma construção com o olhar no passado (texto original) e no presente, buscando a contemporaneidade para a aproximação do pequeno leitor/ouvinte.

Ainda em relação às releituras do conto apresentadas nas versões em português de Portugal e português do Brasil, tornou-se evidente a permanência das histórias tradicionais em obras da literatura infantil. Lindolfo Gomes (2014, p. 5) discorre que todos os povos possuem os seus contos e é "admirável ver como essas tradições, no tempo e no espaço, se submetem ao fenômeno da transplantação sem perder o sinal de origem e passam de um a outro país logrando reviver raças ou povos, as mais das vezes, tão diferentes". 
As releituras provam que as histórias podem ser contadas e escritas de formas distintas, e uma narrativa de origem boca a boca é destacada pelo ditado popular "quem conta um conto aumenta um ponto". Mesmo que as narrativas sofram alterações e influências culturais elas se mantêm presentes no mundo atual. Por fim, compreendemos que os contos tradicionais atuam, significativamente, na formação e na ampliação do repertório da criança, seja leitora ou ouvinte.

\section{Referências bibliográficas}

ALMEIRIM (Portugal). Câmara Municipal. Sopa de pedra: receitas. 2018. Disponível em: < http://www.cm-almeirim.pt/conhecer-almeirim/gastronomia/ item/202-sopa-de-pedra-receitas >. Acesso em: mar. 2018.

AZEVEDO, R. Conto popular, literatura e formação de leitores. Revista Releitura, Belo Horizonte, n. 21, p. 1-8, abr. 2007.

BALÇA, A. Contos tradicionais: língua, cultura e imaginário. In: AZEVEDO, F. (Coord.). Literatura infantil e imaginário. Braga: Centro de Investigação em Estudos da Criança, Universidade do Minho, 2015. p. 27-38.

BRAGA, T. Contos tradicionais do povo português. Lisboa: Publicações Dom Quixote, 1999. v. 1.

CALVINO, I. A tradição popular nos contos de fadas. In: CALVINO, I. Sobre os contos de fadas. Lisboa: Teorema, 2010. p. 97-113.

CANDIDO, A. A literatura e a formação do homem. In: CANDIDO, A. Textos de intervenção. São Paulo: Editora 34, 2010. p. 77-92.

CASCUDO, L. C. Contos tradicionais do Brasil. 2. ed. São Paulo: Global, 2010.

CASTAÑEDA, I. Z. Contos populares: Portugal, Brasil e São Carlos. São Carlos: Ed. da UFSCar, 2005.

COELHO, N. N. Literatura infantil: teoria, análise, didática. São Paulo: Moderna, 2000 .

GOMES, L. Contos populares brasileiros. São Paulo: Melhoramentos, 2014.

GUIMARÃES, R. Calidoscópio: a saga de Pedro Malazarte. São José dos Campos: JAC, 2006.

HALLEWELL, L. O livro no Brasil: sua história. São Paulo: Ed. da USP, 2005.

MACHADO, A. M. Histórias à brasileira: Pedro Malasartes e outras. Ilustradas por Odilon Moraes. São Paulo: Companhia das Letrinhas, 2004. v. 2.

MEIRELES, C. Problemas da literatura infantil. Rio de Janeiro: Nova Fronteira, 2016 . 
PIMENTEL, F. Contos da carochinha. Rio de Janeiro: Quaresma, 1894.

PIRES, M. N. Literatura tradicional. In: CEIA, C. E-Dicionário de termos literários. 2009. Disponível em: < http://edtl.fcsh.unl.pt/encyclopedia/literaturatradicional/>. Acesso em: 13 maio 2019.

RAMOS, A. M. Tendências contemporâneas da literatura portuguesa para a infância e a juventude: desafios atuais. In: DEBUS, E.; JULIANO, D. B.; BORTOLOTTO, N. (Org.). Literatura infantil e juvenil: do literário a outras manifestações estéticas. Tubarão: Copiart; Unisul, 2016. p. 31-58.

RAMOS, F. B.; PANOZZO, N. S. P. Modalidades narrativas: contos lusitanos em quadrinhos. In: RAMOS, F. B.; PANOZZO, N. S. P. (Org.). Mergulhos de leitura: a compreensão leitora da literatura infantil. Caxias do Sul: Ed. da UCS, 2015. p. 75-92.

SALES, M. L. L. A presença das narrativas tradicionais no imaginário dos jovens em idade escolar. Évora, 2014. Manuscrito não publicado.

VIEIRA, A. Histórias tradicionais portuguesas. Ilustração Vanda Romão.

[Alfragide, Portugal]: Caminho, 2018.

Claudia Leite Brandão, doutoranda em Educação na Universidade Estadual Paulista (Unesp Presidente Prudente), é professora da Secretaria de Estado de Educação (Seduc) do estado de Mato Grosso, atuando como professora formadora no Centro de Formação e Atualização dos Profissionais da Educação Básica (Cefapro), em Primavera do Leste (MT). Integrante dos grupos de pesquisa "Formação de professores e as relações entre as práticas educativas em leitura, literatura e avaliação do texto literário", da Unesp Presidente Prudente, e "Alfabetização e letramento escolar" (Alfale), da Universidade Federal de Mato Grosso (UFMT - campus Rondonópolis).

cau_brandao@live.com

Ângela Balça, doutora em ciências da Educação pela Universidade de Évora, Portugal, é professora auxiliar do Departamento de Pedagogia e Educação dessa universidade, membro do Centro de Investigação em Estudos da Criança (CIEC) da Universidade do Minho, e professora visitante na Universidade Estadual Paulista (Unesp), Brasil. Investigadora nas áreas de literatura infantil, educação literária, formação de leitores e ensino da língua materna, em que é autora de várias publicações.

apb@uevora.pt

Recebido em 28 de março de 2019

Aprovado em 28 de abril de 2019 